\title{
Transactional Distance Theory and Compulsory Switching to Remote Teaching due to pandemic in Georgia
}

\author{
GAMBASHIDZE Nino, PhD Student \\ Tbilisi State University, Faculty of Education and Psychology \\ E-mail: ngambashidze@aat.ge \\ ORCID iD: 0000-0002-8084-7185 \\ DOI: $10.46728 / c .18-06-2021 . p 74-84$ \\ CZU: 37.018.43(479.22)
}

\begin{abstract}
This article presents the so-called. "Desk research". It discusses a variety of literature on Transactional Distance Theory. As a part of the research, we reviewed a variety of scientific literature. As a result of the research, many problematic issues in the Georgian educational system were revealed in a new light. Accordingly, the need for practical research in the future was identified. The aim of the present desk research is to create a theoretical-methodological framework on the basis of which we plan to develop a practical research tool in the future.

The study found that frequent communication with students, both synchronously and asynchronously, reduces the degree of student autonomy and forces them to engage in dialogue. This in itself is a guarantee of minimizing the transaction distance. One of the interesting strategies for this is to use informal language in written or oral feedback ("Gio, you wrote well, Kochagh!", "Helen, why didn't you send me an assignment yesterday?"). Personal address to students is important in the asynchronous learning process. It is also important to understand that the student is somehow responsible for publishing his / her assignment in the classroom. Thus, the student becomes accustomed to dialogue with her classmates and feels accountable to them. It is advisable to contact the student's family frequently to find out if they have any problems accessing the Internet or if we can provide the student with a personal device. Sharing personal problems will also reduce the transaction distance and give the student the enthusiasm to engage in dialogue. Moderate use of humor and emotion, hope and encouragement, direct, sincere relationship, will somehow reduce the perception of physical distance, while minimizing the transactional distance.
\end{abstract}

Keywords: Remote Learning, Distance Learning, Transactional Distance Theory, Core principles of Pedagogy: Teaching and Learning, Motivating the students, Involving students in online learning

\section{Introduction}

The Covid-19 pandemic has led to a forced transition to online education for students and teachers in Georgia. Problems related to the quality of teaching-learning, transfer-assimilation of materials and assessment of knowledge were obvious, but their scientific study did not take place, because in the real environment, the existence of many different problems and the lack of physical distance somehow covered the transaction. The importance of the factor of Transactional distance theory may shed light on the problems posed by the forced transition to online teaching, help teachers and administrators develop pedagogical practice, and bring it closer to the core goals of pedagogy: teaching and learning.

\section{Research methods}

This article presents the so-called. "Desk research". It discusses a variety of literature on transactional distance theory. We have developed scientific databases: Scopus, Psychinfo, and the Web of Knowledge to find potentially relevant material on the following terms:

- Transaction distance theory,

- Autonomy, 
- Structure,

- dialog,

- Interaction.

In Scopus alone, we found more than 90 scientific articles on the following issues:

- Distance learning methodology,

- School education,

- Public hearings,

- Comparative-contrast analysis (comparison of traditional, face-to-face learning and distance learning),

- Methodological literature,

- Teacher records and so-called "Descriptive cases".

The studies revealed a comprehensive analysis of the scientific study of the use of technology in the learning process. We got acquainted with scientific publications reflecting the Georgian reality, mostly in online publications and social networks. We have downloaded the abstracts of all the interesting and relevant articles and most of the electronic versions of the article and read them in detail. We have selected and sorted them by photocopying e-books, books and articles. We have also created an electronic citation database, which we keep as a separate bibliography.

The aim of the present desk research is to create a theoretical-methodological framework on the basis of which we plan to develop a practical research tool in the future.

\section{Transactional distance theory}

Prior to the Covid-19 pandemic period, this theory had the status of one among many pedagogical theories. But, due to the forced distance learning caused by the pandemic, it has become crucial. The author of "Transactional Distance Theory" is Michael Moore. In his 1973 book: "Transactional Distance and Adaptive Learning: Planning for the Future of Higher Education 1st Edition" (2017), Moore discusses a student who is far apart in time and space. And the issue of teacher-student relationship. He notes that distancing is not only spatial, but that "without psychological and communicative intersections, potential misunderstandings between the two parties involved in the education process may arise" [30, p. 3].

Which, in the case of forced distance learning, can lead to worse outcomes.

Every teacher must have had a student who chooses to sit in the far corner of the classroom, to avoid the lesson process in an imaginary environment where there is neither homework nor the teacher. It is much easier for such a student to return to reality through inclass education - engaging in conversation, sitting close to the teacher or other pedagogical "tricks". But how does a teacher manage to grab a student's attention when the camera and microphone are off? The "transactional distance theory" offers a way out of such awkward situations.

Our main goal in online learning should be to minimize the transaction distance and maximize the involvement of students in the learning process. The Transactional Distance Theory model might help. M. Moore suggests considering three main variables in distance learning: dialogue, structure, and autonomy. Lack of one means more workload on others.

Moore developed this theory at the dawn of distance learning when there were very few distance learning courses and the material, for the most part, went to students in the form of audio lectures or assignments received by mail. Today, thanks to the widely introduced technological innovations, in the educational space we can meet and teach students directly in synchronous mode. Thanks to the "transactional distance theory", we choose the method that is best to ensure the best results, depending on the age, skills, technology or subject characteristics of our students. 


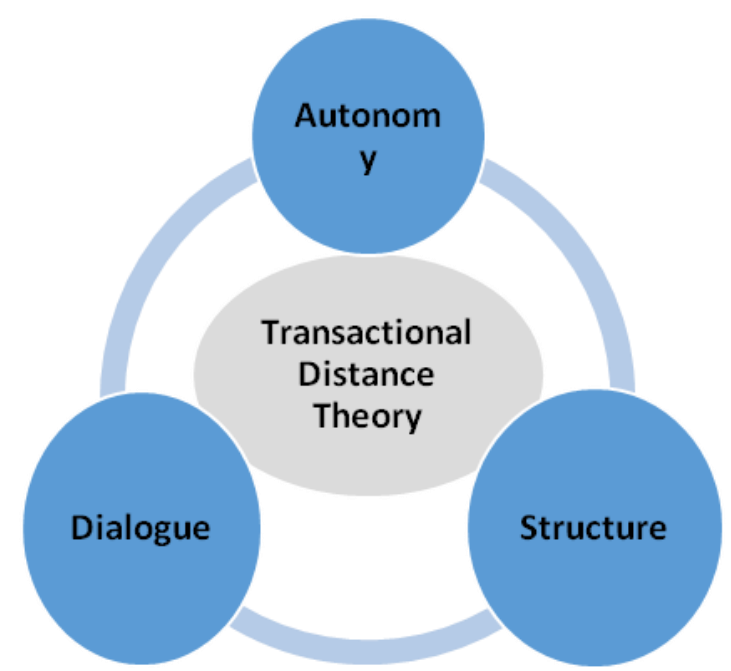

Figure 1: Three Parts of Transactional Distance: dialogue, strucure and autonomy. (Sourse: Tiffany Barton's blog: 'Distance Learning: Theory of Transactional Distance and Dialogue" (Barton, 2020)

\section{Transactional distance theory and the importance of dialogue}

The most important is the dialogue between the teacher and the student, through which the student's maximum concentration on the lesson process is achieved. If we do not talk to students, how do they know what we expect from them, or what they should learn?

The second figure shows how much the importance of autonomy and structure increases when the dialogue space decreases. Consequently, the opportunity for successful learning by the student is lost.

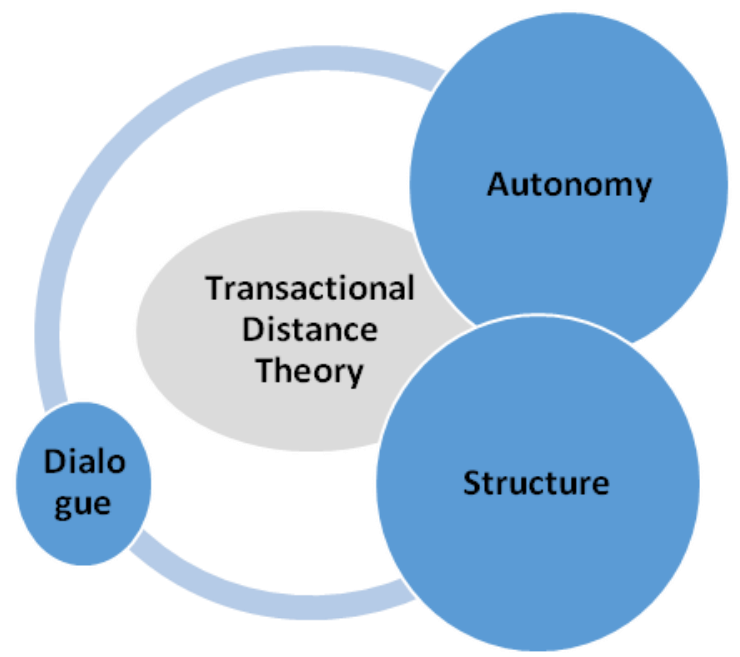

Figure 2: Disbalance and Transactional Distance causes enlarging distance between a teacher and a student.

(Source: Tiffany Barton's blog: `Distance Learning: Theory of Transactional Distance and Dialogue" (Barton, 2020)

\section{Overview of distance learning theories}

To understand better the teaching and learning of distant students and the work of the teacher, we must focus on the perception of distance and space. The "Dictionary of the Georgian Language" defines distance as follows: "Distance [Lat. distantia] distance between the start and the finish ". And the Webster Dictionary is like this: "1. Distance in time and space; 2. The distance between time and space between two points; 3. Behavior delay; 4. A place far away."

When teaching, I think physical distance is less important, because through the Internet we can exchange knowledge and ideas. In the Webster's Third Definition of Distance we see a 
breakdown in the relationship, however we, the teachers, do not want there to be a breakdown in the relationship between the students and us.

Michael J. Moore [27, p. 155], when discussing distance in education, said: "Now the student and the teacher are separated, which is not necessarily due to geographical location, but also has educational and psychological reasons. This is a rift between the partners employed in the education enterprise. This is called the "transaction distance".

How do we understand such a transactional distance between teacher and student? Saba and Shearer [32. P. 36] suggest that the term be understood as "the distance (if you will even crack) of the care expressed by the teacher and the student's outstanding initiative in their own learning". In other words, the transaction distance is the distance that separates students from the teacher's initiative to master the material. If students are not involved in the learning process and do not have an active learning incentive, then this gap in transaction distance is large, no matter how close they are to the teacher physically. But if the teacher, remotely or face-to-face, manages to establish a meaningful learning environment with the right choice of complexity and appropriate material and instills in students a sense of responsibility for their own learning, ensures their heartfelt participation in the process, then the transactional gap diminishes.

Some critics of distance learning believe that a lack of physical closeness, a lack of information transmitted through body language and tone of voice, leads to ineffective learning. But, recalling lectures in a large audience when the teacher cannot even see students sitting at the back of the auditorium.

Bromell wrote ironically on the same subject (Bromell, 2002:73): "It is obvious that a well-planned distance learning course only forces us to 'click' and thus makes the whole learning process more convenient."

When students treat the learning process consciously and responsibly, then it affects learning, knowledge and cognition of new ideas.

I think responsibility for learning can also exist remotely and thus, the lesson is effective, insofar as virtual space provides an opportunity to be able to transfer, receive and exchange ideas, knowledge.

Thus, physical distance and transaction distance are not interdependent data. The lesson is conducted online, in the classroom, or mixed, the aim should be to neutralize the transaction distance and, thus, create a comfortable environment for cognition.

\section{Impact of social distance on transactional distance}

Wegerif [34] discusses the impact of the social dimension in online learning, which has a direct impact on the transaction distance. In a study conducted by the Open University, which included interviews with 21 students involved in interactive online courses, Wegerif found that students' success or failure was directly due to whether they felt involved in the process or outsiders. Thus, the learning process was viewed as a social process because learning depends on how much a person perceives himself or herself as a member of a group.

In conclusion, Wegerif says that this process (meaning distance learning) is a social experience, just as some of the students in the classroom are physically able to engage freely in the middle of a discussion, while some find it very difficult to integrate into the team, experience constant discomfort and prefer to be out of the process.

The student feels involved in the learning process, or isolated, depends on many other factors. For example, one of the factors is access to the Internet. Those who do not have a computer at home, or can not afford the Internet, can not participate fully in the process.

This view is shared by Diana Grodney, who taught hybrid classes at New York University. Tisha Bender, in her book: Discussion-Based Online Learning to Enhance Student Learning, quotes a personal correspondence with Grodney: "I shared this experience [with my class]. They also agreed that in this way we were able to share a family coziness, a collective spirit. As one student pointed out, the lesson became a "hub of education." Another student even compared our lessons to something that is carefully passed from hand to hand throughout the 
week until a new lesson is scheduled. I think such assessments point to a warm environment that can be created online "[3, p. 9].

One factor that Wegerif does not talk about, but is very important in reducing transaction distance, is the teacher's role. It is the teacher who sets the main tone in the class. I think the teacher should definitely develop an educational approach to reduce the feeling of distancing, or indifference, that might result from the distance learning format. This is a rather difficult mission, not only because of the number of students in the class, but also because of the diversity of students.

\section{Transactio the Georgian reality:}

The problem of transactional distance was first raised by XIX c. Enlighters in the Georgian reality. Specifically, in the works of Ilia Chavchavadze and "Tergdaleuli" the issue of "Broken Bridge" ("Otarant's Widow") and the issue of teacher-student relationship ("Glakhis Naambobi" - a Tale of a Bagger, "Gamzrdeli" - The Teacher) were mentioned. The "Tergdaleulis" and their followers, on the one hand, showed the public the problem, and on the other hand, set the stage - they created the artistic face of an "ideal" teacher.

The 20th century inherited the position of Enlighters. Two types of stereotypical, mutually exclusive views of the teachers were formed. Namely: on the one hand, the teacher is "sometimes childless, but a parent of many children" (Ioseb Noneshvili - "Teacher"), on the other hand, an odious figure, well past retirement age, who is mostly ridiculed by mind-boggling, "talented but lazy" students (Nodar Dumbadze - "Me, Grandma, Iliko and Ilarion"), but, in many cases, even a criminal abuser (film "Imereti Sketches" - dir. Nana Mchedlidze, TV-serial "My Wife's Friends" - screenwriter Katie Devdariani, etc.).

In named cases, the teacher is a secondary character.S/He either has a positive effect on the student, or a negative one. The protagonist is always a student, he is attracted to the eyes of the reader or spectator. The author worries about his bad luck. And the teacher is a kind of "circumstance" that determines the psycho-social appearance of the protagonist.

Revaz Inanishvili's "The Far, White Peak" is especially interesting from this point of view. The characters here are ambiguous. It is difficult to determine whether he is a victim or a hero. The story takes place in the 8th grade of one of the schools in the city (this conclusion is proved by the content of the Georgian language and literature subject curriculum established by the National Curriculum [37], when syntactic constructions are taught, including "place adverb". The student has just moved from the village to the city school, so he is a new member of the community, at the same time he is a different member of the homogeneous class. "The boy looked at the class. The whole class was waiting for him with an interested, mocking smile ... Are you failed, Bijou ?! - The eldest boy from the back desk shouted at him in Kakhetian manner. , - exclaimed the teacher, - repeat what is called the adverb of the place .... OHHH, your parents should be unhappy, they think they have sent you to school!" The teacher said in disgust, took a notebook from the table and marked something with a red pen." Accordingly, the student is left to face his own fears: "The boy stood up, put his hands under the skirts of the desk, there was a fog of uncertainty in his eyes again. ... Shindelashvili sat down, bowed his head and started biting his lower lip. The girl sitting next to him noticed that her thin, yellow fingers were trambling" From this situation, there are naturally two solutions: either the boy will forever accept the idea that "he has no place in this society" and chooses to be excluded, or he will become aggressive and later becomes an aggressor. In any case, the transactional crack will take him away from the main goal of education - equipping him with knowledge and upbringing. It seems that the protagonist of Revaz Inanishvili's story, unfortunately, will take the second way this idea is prompted by the "spark" that appears in the finale of the story, which will later be transformed into fire:

It is important to pay attantion the signs that are still relevant in Georgia (whether it is recognized or not). Ignoring such a social difference and consciously or unconsciously turning a blind eye to its existence also leads to the chronic existence of many other problems. 
Two other factors are important to fully understand the problem: 1) The age of the student (adults usually have difficulty adapting to a new environment and the school has to work extra hard in this regard. Etc. 2) Relate the learning material to reality (more precisely, not linking the material in the learning process to the child's personal experience), which is also a common misconception among us.

Will technology enable us to access information that was previously unavailable?

An interview with philologist and teacher Gia Murgulia was published in the electronic edition of the Mothers' Club on February 9, 2021, where he states: "Teacher and school do three main things: they teach this or that subject, they develop skills in students without which it is difficult to hope for success at all, - without willpower, the person does not exist at all, and forms a value system. A good person should be raised by the school. Two of these three, skills development and upbringing systems, look very weak during distance learning. To be on the side of goodness, it needs training and upbringing. " [25]

According to Bruce [6], the use of technology opens up new possibilities that were previously unavailable. For example, technology can do an invaluable service to us if we teach botanics. It will allow us to see in a minute how the flower blooms, something we can not see in nature. But, in this case, do we have the same feeling when we touch a flower? of course no. Because we can not experience the flower with the sense organs - touch its delicate leaves, or feel its benevolence. On the other hand, through technology we will be able to learn much more about the flower than we would by observing it in nature, and thus technology will enable us to do things that were previously impossible.

Thus, at first glance it seems as if technology is really changing knowledge, but to say what we have gained and what we have lost is not so easy. Technology may play a role as an aid and no one will notice its existence as the participants in the discussion turn their attention to the exchange of living thoughts.

This situation proves the existence of a fourth level of Dewey's thinking - reflection in the process of online learning. The perception and analysis of information is likely to deepen if, in a traditional learning environment, particularly important information is repeated several times to convey something to people with different cognitive skills (so that they do not become bored, understand what is being said and be able to see an idea from different angles).

We are dealing with a similar reality when we teach students old Georgian literature. In modern textbooks, texts are accompanied by a dictionary where individual words are explained, but, the meaning remains inaccessible to the student if the teacher does not explain the idea well. The ability to read beyond the lines corresponds to the fourth level of thinking, and the expectation that the student will easily overcome it is exaggerated.

In order to avoid misunderstanding the material learned in the online class, additional explanations are needed. Preferably, these explanations should be given in writing so that the student can return to the material over and over again and finally understand what the author is saying. To comprehend the learning material in the online lesson, it would be good to not only develop the written material, but it is also desirable to include graphic images, sound and video, if possible. Alternating learning activities diversify learning and ensure students' concentration.

\section{Critique of transactional distance theory}

As mentioned, according to Michael Moore's theory, the transaction distance between teacher and student is verified by three variables: dialogue, structure, and autonomy. "In dialogue, Moore refers to the learning relationship between teacher and student, when the speakers listen to each other with respect and share opinions on the essence of dialogue" [22, p.15].

These three, rather important and complex factors are based on the fundamental work of John Dewey [13]. He offers the idea that the educational process is a joint realization of experience and has two sides: psychological (cognitive) and social. Dewey argues that neither 
should be subordinated to the other, nor completely ignored. Dialogue and communication force all parties involved in the process to develop an idea and learn [26].

For Dewey, such a constructivist approach to teaching was the starting point [12]. In his view, the student needs support in accessing and reconstructing the essence of the subject, and this can only be achieved through social interaction and the environment. Only in this way will the student be able to reconstruct the concept and find ways to solve the problem.

This view was reinforced by interpersonal, instructional dialogue, during which the learner is able to acquire and understand knowledge. Dewey described the function of education as the process of developing argumentation and reasoning [13]. Based on his experience as a teacher, Dewey viewed the role of the teacher as a sharer of experience and a leader in development. It divides the path to such a higher level of cognition into four stages: fact-finding, discovery, evaluation, and problem-solving.

Autonomy, as the third variable of Transactional Distance Theory, from a constructivist point of view, means encouraging an active collaborative and responsible learner [35]. The origin of the idea of self-directed learning is linked to Dewey [26], who first noted that giving autonomy to self-development encourages the learner to take initiative, understand the possible consequences of action, and give him or her the choice [12].

For many distance learning researchers, transactional distance is a very important factor and is considered as an analytical framework for understanding [16, 21, 10, 18] "Transactional distance theory" is generally a useful conceptual framework for understanding and explaining the essence of distance learning, but in practice it is a useful source for research hypothesis" [21]

Although this theory has been around for almost 50 years, its critique has not been tried by many. There are also few empirical studies based on this theory that would confirm or refute its content and validity $[18,19]$.

It was interesting to get acquainted with two studies based on an attempt to study the issue on the basis of questionnaires: Bishop et al. [4] were interested in students' perceptions of transaction distance, structure, and dialogue. All three of these factors: transaction distance, dialogue, and structure were discussed in the questions they compiled. All three variables were measured by analyzing specific questionnaires. Transaction distance was measured by two questions, dialogue by one question, and structure by three questions.

The results demonstrated the validity of Moore's theory that transaction distance and dialogue are directly proportional. However, dialogue (a rather complex variable) was measured by only one question. There were no questions about the quality of the dialogue, but only about its frequency. In addition, all three variables were not clearly defined.

This study was soon followed by another [8], where researchers sought to clearly outline the relationship between dialogue, structure, and autonomy. The study interviewed 121 students involved in distance learning. The questionnaires clearly explained the nature of the dialogue - in particular, how often this type of interaction takes place. The structure was interpreted as the transfer and explanation of the material. Autonomy was even interpreted as an assessment of one's own independence. These variables were compared to students' self-esteem. The results showed that only two variables affect the perception of learning outcomes: the higher the perception of the transaction distance, the lower the perception of learning outcomes. The more frequent the discussion, the higher the assessment of the quality of material acquisition and learning in general. These results, in themselves, confirm Moore's theory, although, like the previous study, a simple questionnaire was used. Data were collected only once and the quality of the dialogue was not assessed in this case either, only its frequency was measured.

In another study on the introduction of teacher education and technology, published in Conference Proceedings [7], data were based on 30 teacher-student interactions and measured as a "dynamic model of the system" (in terms of existing patterns of behavior Saba F, Sheare 1994; 8 (1) Verbal conversion was measured through discourse analysis, which combined variables to identify the structure of the program, and by measuring teacher evaluation and student control, 
these variables (the ratio between the amount of dialogue and the structure) were called the transaction distance. That the transaction distance varied according to the dialogue and the structure. As the proportion of the dialogue increased, so did the distance. Is directly proportional to the dialogue, while the structure is inversely proportional.

Although this study corroborated Moore's theory, calculating the number of dialogues and the structure of the program was considered quite problematic. Successful and irrelevant to different types of distance learning.

Also of interest is another study based on which a change in structure during dialogue was examined. This study analyzed the course conducted by the audio-conferencing system (Bunker E et al., 1996) and only compared the structure and dialogue. More than 100 students were involved in this study and the frequency and duration of the dialogue was measured when the structure of the course was discussed in only one aspect (the teacher asked questions to the students).

According to transactional distance theory, different types of interactions and questions revealed the degree of student participation. According to the authors, four experimental procedures were performed, one of which was canceled and the other considered biased. The instrument for measuring interaction was not considered reliable, the samples were not clearly presented, and the principles of grouping were vague. In this case, too, the dialogue was measured in terms of frequency and duration. However, based on the results, it was suggested that certain types of questions asked by the teacher may lead to a desire for dialogue in the student.

According to the authors, both structure and dialogue were important for success, and by increasing the frequency of dialogue, by clearly conveying the structure, the student's desire to be actively involved in the learning process would inevitably increase, as well as the transaction distance.

The following two articles provide a completely different perspective on the study of distance learning variables: $[9,34]$. Course format, satisfaction and acquired knowledge were assessed during the online course. Satisfaction was divided into two aspects, which Moore considered in his theory. The study was based on a questionnaire and the instrument was described in detail. However, quite a small number of responses were not explained (17\%). It was found that there is a relationship between satisfaction and course structure. The more satisfied the students were with the structure and interaction of the course, the more they felt that they had "learned something". This reinforced Moore's assumption that the structure of the course should be appropriate for the learner and that the ambiguity of the structure and the increase in the share of dialogue would reduce the transaction distance.

Very interesting were the responses of 71 students $(87 \%$ of respondents to the questionnaire) presented in this study, which revealed how a change in individual teaching approaches contributed to a change in transaction distance. In this case, too, a survey was conducted through questionnaires aimed at showing students' perceptions (on a 23-point scale) and the results were analyzed according to four variables. The results showed a high ratio of certain variables, which determined the transaction distance.

This study also indirectly addressed the issue that neither face-to-face training nor online tutorials changed transaction distance. It was interesting to note that "online learning" somehow led to an increase in distance and interaction barriers, although it was not clear what was called "online learning". The credibility of the study was demonstrated by the involvement of "experts" and "educators" in the study, and their participation was quite active. The report said that different methods (quantitative, observation, interview) were needed to measure the transaction distance, which would make it easier to understand this phenomenon.

In conclusion, it can be said that "transactional distance theory" is more descriptive and can not define anything in advance. But, shows the obvious interdependence of the variables. Moreover, Moore's conception of transactional distance has significantly altered educators' approaches to distance learning in terms of broad social rather than narrow field research [26]. 


\section{Conclusions}

- "Transactional distance theory" is based on humanistic and behaviorist ideology.

- Michael Moore first formulated structure and dialogue as its components when formulating the Transactional Distance Theory. And the third factor - autonomy was later added [27].

- Structure, dialogue, and autonomy are interdependent and absolutely essential factors for the successful implementation of distance learning [27].

- Michael Moore did not explicitly present the action of the constituent factors of his theory, which later led to numerous errors in research [19].

- Surveys devoted to autonomy and self-education were usually based on closed-ended questions and scales.

- Most of the research on the "transactional distance theory" was viewed from a positivist point of view. Moore's theory and focused on correlating complex concepts and establishing statistically significant relationships (e.g., the interdependence of autonomy and the results of acquired knowledge).

- None of the studies fully confirmed or denied the transaction distance.

- All studies suggested that the data collected from interviews and observations should be analyzed in the future. [4, 8, 7, 32, 9, 23]

\section{Acknowledgments:}

Zakaria Kitiashvili, the head of my doctoral program, provided invaluable assistance to me in my research.

I would also like to thank my friend Giorgi Gvishiani for temporarily giving me all the scientific bases available to him, without which I would not be able to get acquainted with such a wide range of scientific literature.

And finally, I would like to express my gratitude to another friend of mine - Nino Dolidze, who spared no effort, read the article many times and discovered all the technical or logical shortcomings, which were so important to eliminate.

\section{BIBLIOGRAPHY}

1. ANDERSON, J. A.. Acknowledging the Learning Styles of. In L. B. Chism, Teaching for Diversity: New Directions for Teaching and Learning,. San Francisco: Jossey-Bass. 1992, pp. 19-33

2. BARTON, T. Technotes. 2020. Retrieved 02. 10, 2021, from TCEA: https://blog.tcea.org/TRANSACTIONAL-DISTANCE-THEORY/

3. BENDER, T. Discussion-Based Onlaine Teaching to Enhance Student Learning. Theory, Practice, and Assessment. Sterling, Virginia: Stylus. 2003

4. BISCHOFF WR et al. Transactional distance and interactive television in the distance education of health professionals. American Journal of Distance Education, 1996, pp. 4-19.

5. BROMELL, N. Summa Cum Avaritia. Harper's Magazine, 02.2002, pp. 71-76.

6. BRUCE, B. Dewey and Technology. Retrieved from International Literacy Association. 1998, 11: http://www.readingonline.org/electronic/jaal/Nov_column.html

7. BUNKER E. et al.. A study of transactional distance in an international audioconferencing course. Proceedings of Seventh International Conference of the Society for Information Technology and Teacher Education, 1996, pp. 40-44. Phoenix: Society for Information Technology and Teacher Education .

8. CHEN Y. J., WILLITS F. K. A path analysis of the concepts in Moore's theory of transactional distance in a videoconferencing environment. Journal of Distance Education, 1998;13(2), pp. 1-65. 
9. CHEN, Y. Transactional distance in World Wide Web learning environments. Innovations in Education and Teaching International, 2001;38(4), pp. 327-338.

10. COLLINS M.P., MURPHY K. L. Development of communication conventions in instructional electronic chats. Journal of Distance Education, 1997;12(1), pp. 177-200.

11. DELGATY, L. www.interchopen.com. 2018, 09, Retrieved 02.15.2021, from Open access peer-reviewed chapter: https://www.intechopen.com/books/interactive-multimediamultimedia-production-and-digital-storytelling/transactional-distance-theory-a-critical-viewof-the-theoretical-and-pedagogical-underpinnings-of-e-

12. DEWEY, J. Democracy and Education. Middlesex: Echo Library, 2007

13. DEWY, J. What is Thought? Kindle Edition: Endymion Press, 2018

14. DREYFUS, H. L. amazon.com. 2008. Retrieved 02.07.2021 from https://www.amazon.com/Internet-Thinking-Action-Hurbert-Dreyfus/productreviews/0415228077? pageNumber $=2$

15. EDUCATION, P. Validity Brief: Panorama Student Survey. 01.2019. Retrieved 23.11.2020, from Panorama: https://go.panoramaed.com/hubfs/Panorama_January2019\%20/Docs/validity-brief.pdf

16. GARRISON, R. Theoretical challenges for distance education in the 21 st century: A shift from structural to transactional issues. The International Review of Research in Open and Distance Learning, 2000, 1492-3831.

17. BASILAIA G., KVAVADZE D. Transition to Online Education in Schools during a SARSCoV-2 (Research Article ), 04.05.2020. Retrieved 02.07.2021, from MODESTUM Open Acess: https://files.eric.ed.gov/fulltext/EJ1263561.pdf

18. GOEL L., ZHANG P., TEMPLETON M. Transactional distance revisited: Bridging face and empirical validity. Computers in Human Behavior, 2012;28(4), pp.1122-1129.

19. GORSKY P., CASPI A. A critical analysis of transactional distance theory. The Quarterly Review of Distance Education, 2005;6(1), pp. 1-11.

20. GUIDE, P. U. Panorama Student Survey, 2019. Retrieved 11.23.2020, from Panorama Education: https://panorama-www.s3.amazonaws.com/files/panorama-studentsurvey/UserGuide.pdf?_hssc=17850406.2.1606157239767\&_hstc=17850406.20c9c4435f4 2d6c1f83a8c8dd70b6b8b.1606132388119.1606150143424.1606157239767.3\&_hsfp=13019 10431\&hsCtaTracking=ef4fd9f4-f6c2-4

21. JUNG, I.. Building a theoretical framework of web-based instruction in the context of distance education. British Journal of Educational Technology, 2001. 32(5), pp. 525-534.

22. JANASHIA S. "Concept of Distance Learning and its theoretical foundations". Managing the Distance Learning: A Practical Textbook for School Administrators, Tbilisi, 2021, pp. 7-23

23. KANUKA H., COLLETT D., CASWELL C. University instructor perceptions of the use of asynchronous text-based discussion in distance courses. American Journal of Distance Education, 2002; 16(3), pp. 151-167.

24. McKEACHIE, W. J. Doing and Evaluating Research on Teaching. Chaper 6: "6 Roles of a Teacher", Chapter 24: "Personalisation of Education"; Chapter 25: "Researching Teaching and Assessment". 1978. In W. J. McKeachie, Teaching Tips, A Guide for the Beginning College Teacher, 7th ed. (pp. 68-82, 244-256, 257-263 ). Lexington, Mass.: Heath and Company.

25. MomsEduGe. 2021. Retrieved 02.09.2021, from www.momsedu.ge: https://momsedu.ge/

26. MOORE MG, ANDERSON WG. Handbook of Distance Education. 2nd ed. Mahwah, New Jersey: Lawrence Erlbaum, 2007

27. MOORE MG, KEARSLEY G. Distance Education: A Systems View of Online Learning. 3rd ed. Belmont, California: Library of Congress, 2012

28. MOORE, M. G. The individual adult learner. In Adult Learning and Education, ed. M. Tight. London: Croom Helm, 1984

29. MOORE, M. Transactional Distance and Adaptive Learning: Planning for the Future of Higher Education 1st Edition. New York: Routledge, 2017 
30. PANORAMA. Panorama Student Survey, 08.2014. Retrieved 03.2018, from https://www.panoramaed.com/panorama-student-survey

31. GORSKY P., CASPI A., A critical analysis of transactional. In The Quarterly Review of Distance Education, 6(1) 2005, pp. 1-11.

32. SABA F., SHEARER R.L. Verifying key theoretical concepts in a dynamic model of distance education. American Journal of Distance Education., 08.1994, pp.136-59.

33. SABA, F., SHEARER R. L. Verifying Key Theoretical Concepts in a Dynamic Model of Distance Education. The American Journal of Distance Education, 08.1994, pp. 36-59.

34. STEIN D.S. et al.. Bridging the transactional distance gap in online learning environments. American Journal of Distance Education, 02. 2005, pp. 105-118.

35. TAM, M. Constructivism, instructional design, and technology: Implications for transforming distance learning. Educational Technology and Society, 03.2000, pp. 50-60.

36. WEGERIF, R. The Social Dimension of Asynchronous Learning Networks. In The Journal of $\begin{array}{llll}\text { Asynchronous Learning Networks } & \text { 1998, }\end{array}$ http://www.aln.org/alnweb/journal/vol2_issue1/wegerif.htm.

37. GEOSTAT. National Statistics Office of Georgia, 2021. Retrieved 02.07.2021, from https://www.geostat.ge/ka/modules/categories/59/zogadi-ganatleba

38. The Portal of National Curriculum 2019-2020. Retrieved 02.06.2021, from http://ncp.ge/files/subjects/qartuli/programis\%20shinaarsi/qartuli\%20\%20VIII\%20klasi\%20$\% 20$ programis\%20shinaarsi.pdf

39. Ministry of Education, Science, Culture and Sports of Georgia, 2020. https://www.mes.gov.ge/content.php?id=11404\&lang=geo. Retrieved 02.07.2021, from https://www.mes.gov.ge/content.php?id=11404\&lang=geo

40. Ministry of Education, Science, Culture and Sports of Georgia, 02.04.2021. mes.gov.ge. Retrieved 02.07.2021, from https://www.mes.gov.ge/content.php?id=11590\&lang=geo 